\title{
APnet, an innovative multidisciplinary medical information platform for acute pancreatitis
}

1. Surgical Intensive Care Unit (SICU), Department of General Surgery, Jinling Hospital, Medical School of Nanjing University, No. 305 Zhongshan east road, Nanjing, 210002, China. Contributors: Yang Fei and Wei-qin Li conceived and designed the study, interpreted the data and wrote the paper.

http://dx.doi.org/10.1590/1806-9282.65.2.118

\section{SUMMARY}

The APnet information platform aims at assisting patients suffering from acute pancreatitis, health professionals and patients' relatives in the acute pancreatitis care pathway by providing an integrated information system. The system consists of a mobile platform and a Clinical Information System. The system is currently on the formal operation phase focusing on addressing the needs of citizens of China.

KEYWORDS: Pancreatitis. Pancreatitis, acute necrotizing. Smartphone. Cell phone. Health information systems.

\section{INTRODUCTION}

With the increasing number of acute pancreatitis (AP) patients in China, the limited financial input and low medical technical level in primary clinics can hardly satisfy patients' demand for medical services. Moreover, follow-up and management for discharged AP patients are neglected by most hospitals at present, which can lead to recurrence and severe complications of AP. Meanwhile, with the rapid development of internet technology and the multiplying growth of broadband speed, the use of information/communication technologies and web service in medical service are growing increasingly popular, providing remote communication or services that assist with certain health-care activities, thus lowering health-care costs and improving health-care quality ${ }^{1-3}$. Therefore, it is urgent to build a information platform to facilitate communication between doctors and AP patients.

In the present study, we built a multidisciplinary medical information platform named APnet for AP to help Chinese clinicians who need to make difficult clinical decisions concerning their patients and increase consultancy channels with doctors, providing them with knowledge of the latest developments in pancreatology, facilitating the two-way referral of patients, and providing convenient consultation for AP patients after discharge. 


\section{PLATFORM ARCHITECTURE}

The architecture of the APnet platform can be found in figure 1 . With all core elements modularized, the APnet platform focuses on the establishment, linkage, and integration of various services. As far as the server is concerned, data-sets are managed by MySQL RDBMS and used by the Apache server. HTML and PHP5 languages which were included in Apache are used in interaction with the MySQL RDBMS for the display of APnet web statistics in real-time and/or updated. It interacts through a "reverse proxy" with the associated Windows server. As far as data exchange is concerned, it adopts the service-oriented architecture standard for the message exchange interface and the HL7/XML standard for the message delivery formats among systems. As far as the client is concerned, an application launched by the web browser will enable access to its web pages depending on user profiles. As far as security is concerned, APnet platform is hosted on a secure Windows server operating system protected by a firewall. The data and messages in the message exchange interface must follow WS-Security regulations to include the encryption setting and the signature in order to ensure the non-repudiation and consistency of the data and messages. The computer languages used are HTML/XHTML, JAVA, PHP, and Visual C++.

The APnet platform contains six modularized core elements: (1) medical service resources registration, (2) remote medical information transmission, (3) electronic healthcare record management, (4) service log and system monitoring, (5) healthcare institutions interface, and (6) information security management.

The information platform can play the role of different medical institutional healthcare services as well as the role of an e-counter website and Web Service Provider portal. Through service resources, registration, and integration of other healthcare service resources, it can internally link up with the various model health service e-counters and externally interface with the available healthcare resources to provide assistance requested by different types of users.

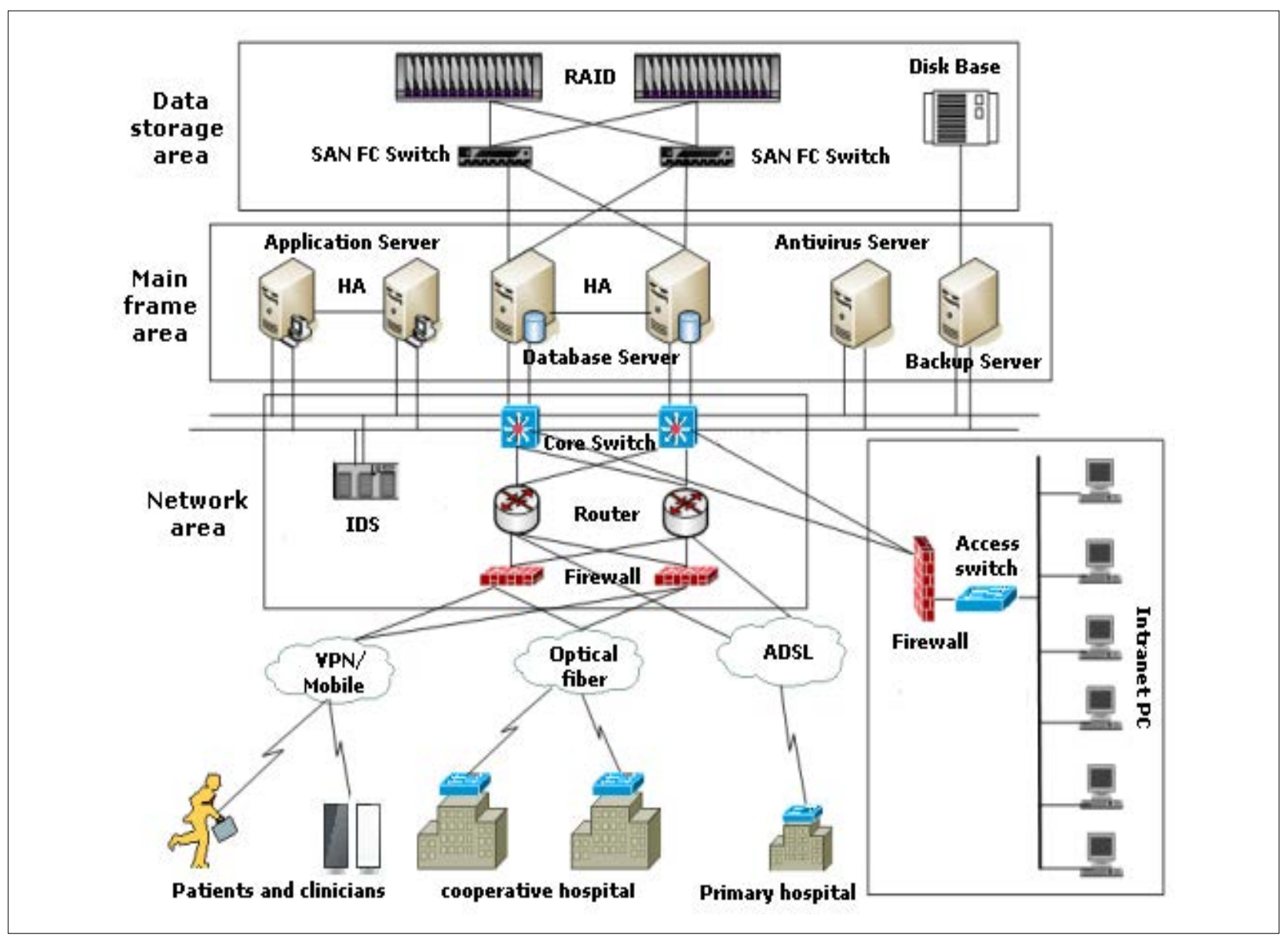

FIGURE 1 - THE ARCHITECTURE OF THE APNET INFORMATION PLATFORM 


\section{SYSTEM FUNCTION DESIGN}

The APnet platform is divided into 7 functional architectural areas, as shown in Figure 2 : (1) service portal; (2) medical service resources registration; (3) electronic healthcare record service; (4) remote clinical and physiological information transmission system; (5) healthcare resources interface service; (6) remote health education; (7) information platform core operation services.

The service portal utilizes a single service window that provides healthcare information and resources inquiry and performs operations for public and e-counter attendants. It provides an integrative, continuous, and shared digital healthcare service media and acts as a regional healthcare and living resources information integration center too. The service resources registration application is comprised of a healthcare service resources repository which includes professional healthcare and living support by concentrating service resources information provided by various healthcare modes. It also acts as a media providing member service requirements to allow for a healthcare and living resources sharing environment. Moreover, the various healthcare service modes can provide essential information of service content through registered items of the remote healthcare information platform and be displayed in the service resources usage interface of the platform portal to provide inquiry of such resources by the users. The electronic healthcare record is comprised of an electronic healthcare record index and electronic healthcare record summary. Presently, the remote healthcare information platform mainly uses the identity card number to authenticate member identity. Aside from being an electronic healthcare record index with all the necessary information of the member, it also simultaneously stores the member's healthcare service log in various healthcare modes. The detailed factual healthcare information will not be stored in the information platform but in the information systems of various healthcare service modes. If needed, the information may be searched and read through the data exchange mechanism between systems and displayed afterward in an electronic healthcare record summary. The remote clinical and physiological information transmission system can assist the various healthcare service modes by carrying out clinical information or physiological signal measurement and management to record, store, and transfer the various clinical information or physiological signals obtained with measuring instruments at the member end. The various healthcare service modes may also obtain member hospital discharge preparatory information by interfacing with the remote healthcare information platform and the long-term healthcare information network, thereby establishing continuous healthcare service. Then we can provide appropriate requirements and personalized healthcare service in line with its healthcare requirements after discharge; healthcare service can effectively achieve healthcare information sharing and minimize the waste of unnecessary healthcare resources. Users certified by single

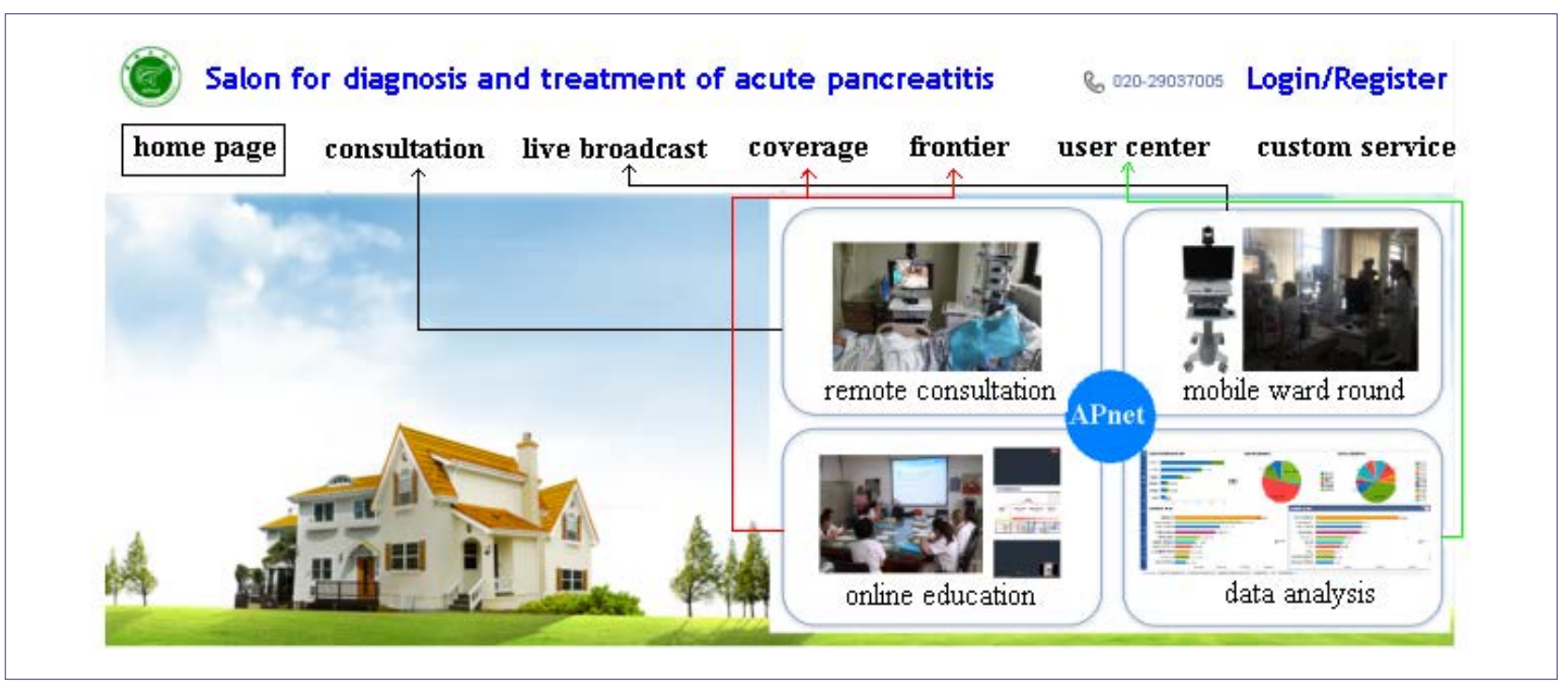

FIGURE 2 - THE HOMEPAGE OF APNET INFORMATION PLATFORM WEBSITE 


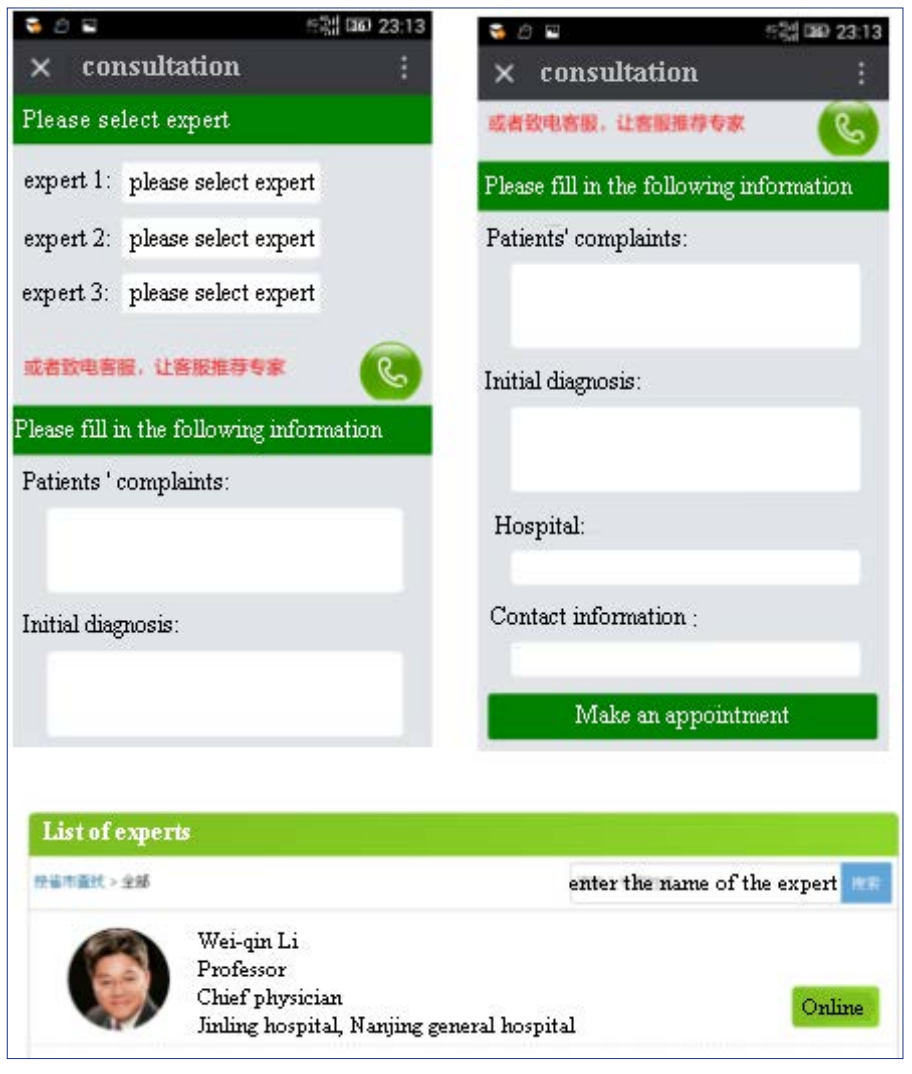

FIGURE 3 - REMOTE CONSULTATIONS APPLICATION BY APNET PLATFORM

sign-on via the remote healthcare information platform may also use remote health education services. Remote health education services may also be useful to members of various healthcare service modes. In remote health education learning services, the information platform disseminates health education content to a member's personal computer or mobile phone.

The information platform core operation provides two mechanisms for the entire information platform: single sign-on mechanism and information security exchange mechanism. The information security exchange mechanism is comprised of the Public Key Infrastructure and WS-Security. To ensure the completeness, confidentiality, authentication, and non-repudiation of the healthcare service information, the APnet platform utilizes PKI technology and employs different public and private keys to carry out the electronic signature mechanism.

\section{SYSTEM EVALUATION AND DEPLOYMENT}

On system deployment, the remote healthcare information platform, user, health admin- istration, and social administration healthcare resources are connected through the internet. Meanwhile, the provision of linkage and authorization via the IDC computer room service platform can facilitate the sharing of various healthcare resources as shown in Figure 2. The information platform is placed in the co-location computer room (IDC computer room) of the Internet Service Provider (ISP). The FTTB optical fiber broadband's dedicated line is connected to the internet, ensuring transmission speed and system quality of the data channel. On internet security prevention deployment, all internet access and inquiry requests must be confirmed by the preventive firewall, the intrusion prevention system (IPS), and anti-virus security prevention before being allowed to connect to the internal application system internet.

Regarding the backup mechanism of the application system service, a two-set design is installed regardless of the internet security protection equipment or application server to ensure non-interrupted system service. The internet security protection equipment will accommodate the redundant requests of the application server and the back-end service support of the application server request. Under emergency and necessary circumstances, the backup server will replace the original server as a system backup.

The deployment of the APnet information platform in public hospitals, doctors' and patients' mobile phone terminals is currently in progress. Analysis of the system performance and comparison with the existing health-care services is expected to demonstrate its clinical acceptance and effectiveness in diagnosis and managing AP.

The APnet platform was officially launched on November $26^{\text {th }}, 2016$. Up to July $1^{\text {st }}, 2017$, the information platform had more than 2,000 users. Through the platform, there were 87 remote consultations (Figure 3), 32 bidirectional referrals, 58 remote teaching, eight live academic conferences about AP, and 120 latest progress of AP. The APnet platform includes more than 7,000 patients with AP. In the future, prospects for the development of the APnet platform is worth users' expectation. More functional modules will be incorporated into it, such as an AI-based decision support system and a pancreatitis biological sample database. Coverage in the country will be further expanded ${ }^{4-6}$. 
RESUMO

A plataforma de informações APnet tem como objetivo auxiliar pacientes que sofrem de pancreatite aguda, profissionais da saúde e familiares de pacientes no percurso de cuidados para a pancreatite aguda, oferecendo um sistema integrado de informações. O sistema consiste de uma plataforma móvel e um Sistema de Informações Clínicas. Ele atualmente se encontra na fase de operação formal, focado em atender às necessidades dos cidadãos da China.

PALAVRAS CHAVE: Pancreatite. Pancreatite necrosante aguda. Smartphone. Telefone celular. Sistemas de informação em saúde.

\section{REFERENCES}

1. García-Sáez G, Hernando M, Martínez-Sarriegui I, Rigla M, Torralba V, Brugués E, et al. Architecture of a wireless personal assistant for telemedical diabetes care. Int | Med Inform. 2009;78(6):391-403.

2. Endean ED, Mallon LI, Minion DI, Kwolek Cl, Schwarcz TH. Telemedicine in vascular surgery: does it work? Am Surg. 2001;67(4):334-40.

3. Källander K, Tibenderana JK, Akpogheneta OJ, Strachan DL, Hill Z, ten Asbroek $\mathrm{AH}$, et al. Mobile health (mHealth) approaches and lessons for increased performance and retention of community health workers in lowand middle-income countries: a review. | Med Internet Res. 2013;15(1):e17.

4. Fei $Y, H u$ J, Li WQ, Wang $W$, Zong GQ. Artificial neural networks predict the incidence of portosplenomesenteric venous thrombosis in patients with acute pancreatitis. J Thromb Haemost. 2017;15(3):439-45.

5. Fei $Y, H u$ J, Gao K, Tu J, Li WQ, Wang W. Predicting risk for portal vein thrombosis in acute pancreatitis patients: a comparison of radical basis function artificial neural network and logistic regression models. J Crit Care. 2017;39:115-23.

6. Fei Y, Gao K, Hu J, Tu J, Li WQ, Wang W, et al. Predicting the incidence of portosplenomesenteric vein thrombosis in patients with acute pancreatitis using classification and regression tree algorithm. J Crit Care. 2017:39:124-30 